\title{
Narrativa, experiência e formação: o diálogo com as crianças na constituição de tornar-se professora
}

\section{Narrative, experience and training: dialogue with children within the process to become a teacher}

\author{
Gabriela Barreto da Silva Scramingnon*
}

\begin{abstract}
RESUMO
Este artigo, fruto de uma pesquisa de doutorado, toma como objeto de estudo as narrativas de uma professora da Educação Infantil e dos anos iniciais do ensino fundamental de uma instituição pública municipal, e tem como objetivo discutir a constituição da docência como processo que se dá na relação com as crianças. A estratégia metodológica, sustentada no diálogo com Walter Benjamin (1994; 1995; 2006) e Martin Buber (2003; 2009; 2012), foi de analisar as narrativas da trajetória da professora no cotidiano escolar em seu diálogo com as crianças. O caderno com os registros dessas conversas converte-se, dessa forma, em empiria de pesquisa. Assim, as narrativas biográficas são compreendidas enquanto metodologia de pesquisa e de formação (JOSSO, 2004). As análises destacam: as crianças como depoentes privilegiados de sua condição, e que nos dão pistas sobre as relações que estabelecem com os professores na escola, indicando possibilidades outras para o desenvolvimento da prática pedagógica; a docência como processo inacabado, aberta a construções e desconstruções; as narrativas biográficas como caminho para a constituição de uma identidade profissional; a importância de espaços e tempos garantidos na escola para que os professores produzam seus registros, considerando-os como possibilidade de pensar o trabalho. Nesse sentido, como experiência, a pesquisa e o texto narrativo são acontecimentos do presente.
\end{abstract}

Palavras-chave: Narrativa. Professores. Criança. Escola. Formação.

* Universidade Federal do Estado do Rio de Janeiro. Rio de Janeiro, Rio de Janeiro, Brasil. E-mail: gabrielabasil@gmail.com - https://orcid.org/0000-0002-3819-8302 


\begin{abstract}
The aim of the present study - which results from a doctoral research - is to address "becoming a teacher" as a process taking place through teaching professionals' relationship with children. It was based on narratives of an Early Childhood education and elementary school teacher from a municipal public institution. The methodology adopted in the current study was based on the theory by Walter Benjamin (1994; 1995; 2006) and Martin Buber $(2003 ; 2009 ; 2012)$; it lied on analyzing the narratives about the aforementioned teacher's routine at the assessed school through her dialogue with children. The notebook presenting records of these conversations became the instrument of research empiricism. Thus, biographical narratives were herein understood as research and training methodology (JOSSO, 2004). Analyses have highlighted that children are privileged deponents of their condition, who give clues about the relationships they establish with teachers at school - therefore, they indicate other possibilities for pedagogical practice development; as well as that teaching is an unfinished process open to constructions and deconstructions; that biographical narratives are the way to build one's professional identity; that the space and time at school play an important role in enabling teachers to make their registrations and use them, later on, to think about their own work. If one takes into consideration research and narrative texts as register of lived experiences, it is possible seeing them as events happening in the present.
\end{abstract}

Keywords: Narrative. Teachers. Child. School. Training.

\title{
Introdução
}

As narrativas do caderno de registros diários de uma professora da educação infantil e dos anos iniciais do ensino fundamental de uma instituição pública municipal, tomadas como empiria de pesquisa, fundamentam a discussão proposta neste texto. $\mathrm{O}$ estudo teve por base uma pesquisa de doutorado em que a produção do conhecimento caminhou na direção de analisar, a partir do diálogo com as crianças, a possibilidade de ensinarem aos professores a importância de estarem sempre se questionando a respeito de como fazem e o que fazem no cotidiano escolar, compreendendo a formação como processo inacabado. Nesse sentido, o que está inacabado sofre, todo tempo, um processo de construção e reconstrução.

$\mathrm{Na}$ perspectiva de que as crianças não reproduzem diretamente o mundo dos adultos, mas são capazes de estabelecer uma nova relação com o que o mundo 
lhes oferece, na escola convidam professores a pensarem novas perspectivas de trabalho, considerando o imprevisto e o espontâneo apresentados por elas, mostrando como o cotidiano escolar, como algo ponderado e planejado diretamente pelos adultos, pode ser diferente.

O referencial teórico-metodológico do estudo está delineado com base em Walter Benjamin e Martin Buber, cujos conceitos instigam as perguntas centrais da discussão proposta. Como as crianças revelam em seus discursos e brincadeiras a compreensão que têm de si, dos outros e do mundo social? O que falam da escola? Na relação com os professores, que temas, conversas e perguntas as crianças trazem? Que aspectos - nas narrativas dos professores a respeito de sua própria prática - podem contribuir para a produção do conhecimento no sentido de um outro jeito de fazer na escola?

$\mathrm{Na}$ compreensão de que o trabalho dos professores precisa ser entendido a partir de uma perspectiva que dê conta de pensar o homem em sua totalidade e singularidade, as contribuições da filosofia benjaminiana se colocam profícuas: o conceito de narrativa; experiência; o trabalho com fragmentos; a ideia de construção e desconstrução; a história no entrecruzamento de presente, passado e futuro; a concepção crítica de criança e infância; o homem como sujeito histórico, social, produtor de linguagem, sempre imerso em uma coletividade. Para Benjamin (1994), ouvinte e narrador partilham de uma experiência comum e do interesse em conservar o narrado para evitar a degradação da experiência. $\mathrm{O}$ desafio de narrar o passado é o de compreender que todos os acontecimentos importam.

Ao tratar da educação como relação, Buber indaga: "que possibilidades são reconhecidas à escola para este tipo de educação?” (BUBLER, 2012, p. 91). Para o autor, a educação precisa ser alicerçada no diálogo, tendo a escuta e a resposta como condutores das relações e das práticas educativas. Educação é responsabilidade com o mundo: voltar-se para o outro, com relações autênticas, reconhecer o outro como um outro diferente de si e, diante desse reconhecimento, dirigir ao outro uma resposta que atenda à sua necessidade. Responder ao que nos acontece.

Nesse sentido, este texto, como desafio de tecer com a escrita as narrativas do encontro de uma professora com as crianças e suas infâncias no cotidiano escolar, aborda, no primeiro momento, as contribuições da filosofia antropológica de Benjamin, na compreensão da narrativa como percurso investigativo. Em seguida, no diálogo com as crianças, a partir do olhar delas para a escola, a prática pedagógica é tensionada, possibilitando a reflexão da formação do professor como processo inacabado, de reflexão que se dá na relação com os sujeitos que vivem o cotidiano. As considerações recuperam os principais achados do estudo, enfatizando a necessidade de pensar a formação dos professores como espaço no qual tenham o direito de narrar suas histórias. 


\section{Memórias, registros, narrativas, escritas de si}

$\mathrm{Na}$ crítica ao projeto da modernidade, Benjamin denunciou o empobrecimento da linguagem expressiva, a incapacidade de ligação entre presente e passado, a incapacidade de narrar e estabelecer elos de coletividade, e de intercâmbio de experiência. O conceito de experiência, central na obra de Benjamin e fundamental neste estudo, é entendido em um sentido amplo, mais abrangente do que aquilo que se expressa no senso comum. Tal conceito é encontrado em vários de seus escritos. Em "Experiência e pobreza", de 1933, e "O narrador - considerações sobre a obra de Nikolai Leskov", escrito em 1936 (Benjamin, 1994), esse conceito vai se desenhando. Em "Experiência e pobreza", ele narra sobre um ancião que antes de morrer diz aos seus filhos que há um tesouro em suas terras, situando assim a experiência como sabedoria de vida, como resultado das atividades de uma vida inteira que, contada aos mais jovens pelos mais velhos, permite a continuidade da tradição e dela própria. Trata-se da experiência que sempre foi comunicada aos jovens,

[...] de forma concisa, com a autoridade da velhice, em provérbios; de forma prolixa, com sua loquacidade, em histórias; muitas vezes como narrativas de países longínquos, diante da lareira, contadas a pais e netos (BENJAMIN, 1994, p. 114).

No texto "O narrador - considerações sobre a obra de Nikolai Leskov" (Benjamin, 1994), o conceito de experiência ganha uma dimensão coletiva e a principal discussão que o atravessa é a crítica contundente do autor ao desaparecimento da arte de narrar. A experiência se torna cada vez mais escassa na modernidade, em função da incapacidade dos sujeitos de narrarem acontecimentos memoráveis, dos avanços tecnológicos característicos do progresso, o que acaba por minimizar a memória coletiva. $\mathrm{O}$ narrador em Benjamin é aquele que sabe dar conselhos, uma vez que dar conselho é visto muito mais como possibilidade de continuar a contar uma história do que como um guia prático para a vida. A narrativa não busca informar, "ela mergulha a coisa na vida do narrador para em seguida retirá-la dele. Assim se imprime na narrativa a marca do narrador, como a mão do oleiro na argila do vaso" (BENJAMIN, 1994, p. 204). 
Benjamin faz uma diferenciação entre o historiador que escreve histórias e o cronista que narra histórias. Para ele, é impossível ao historiador convencional simplesmente apresentar os acontecimentos a que se refere, sem explicá-los de uma forma ou de outra. Mostrar os acontecimentos cotidianos como exemplos de devir do mundo é tarefa do cronista. É o cronista que narra os acontecimentos sem, de antemão, fazer distinção entre os grandes e os pequenos, levando "em conta a verdade de que nada do que um dia aconteceu pode ser considerado perdido para a história" (BENJAMIN, 1994, p. 223). Crítico do seu tempo, empreende uma filosofia contra o esquecimento.

Ao formular teses sobre o conceito de história e tecer uma crítica à ideologia do progresso, convida a pensar categorias temporais a partir da crítica à compreensão da vida como sequência de etapas evolutivas, considerando o entrecruzamento entre passado, presente e futuro. Com base nessa perspectiva de temporalidade, a história não surge de um ponto de partida primordial, ela pode ser constantemente refeita e recontada. O declínio da narrativa se vincula à perda gradativa da memória e à incapacidade de deixar rastros. Assim, Benjamin alertava para a importância da experiência narrativa como condição da historicidade do ser humano (BENJAMIN, 1994). No que tange à formação de professores, o resgate de uma memória que revele uma experiência significativa traz possibilidades não só de ressignificação do já vivido, mas também de uma ação no presente.

É nesse tempo histórico de intensidade e não de cronologia, é nesse presente que os encontros acontecem. Na vida, no cotidiano, e por que não, na profissão? A docência tem sido lugar de encontro entre as crianças e seus professores? E, para além do encontro, os professores têm tido espaço para a narrativa de suas experiências? Os processos de formação têm considerado a apropriação retrospectiva da trajetória de vida dos professores? A rememoração faz emergir o que se viveu, experimentou, aprendeu; e pode trazer uma reminiscência, imagem súbita de algo que repousava em algum canto quase inacessível de nossas vidas, pois "o passado traz consigo um índice misterioso que impele à redenção" (BENJAMIN, 1994, p. 223). O passado precisa ser olhado a partir do encontro com o presente, e tal encontro propõe uma revolução na maneira como o pensamento se constrói. Em "escavando e recordando", Benjamin diz:

Quem pretende se aproximar do próprio passado soterrado deve agir como um homem que escava. Antes de tudo, não deve temer voltar sempre ao mesmo fato, espalhá-lo como se espalha a terra, revolvê-lo como se revolve o solo. Pois fatos nada são além de camadas que apenas à exploração mais cuidadosa entregam aquilo que recompensa a escavação. Ou seja, as 
imagens que, desprendidas de todas as conexões mais primitivas, ficam como preciosidades nos sóbrios aposentos de nosso entendimento tardio, igual a torsos na galeria do colecionador. E certamente é útil avançar em escavações segundo planos. Mas é igualmente indispensável a enxadada cautelosa e tateante na terra escura. E se ilude, privando-se do melhor, quem só faz o inventário dos achados e não sabe assinalar no terreno de hoje o lugar no qual é conservado o velho (BENJAMIN, 1995, p. 239).

Escavar e recordar memórias a partir dos diálogos estabelecidos com as crianças exige, como propõe Benjamin, assinalá-las no terreno do hoje. Recorrer à memória do passado para falar do presente situa de que lugar da experiência estamos olhando, e de como o lugar da pesquisa não está distante do pesquisador. Narrar o vivido com as crianças na trajetória de professora tem relação com minha experiência de vida, com o que me constitui enquanto professora, com os momentos em que fui surpreendida por elas, numa relação que deixou marcas na minha história.

Nesse sentido, a narrativa ultrapassa a dimensão individual do trabalho do professor. E por que narrar e registrar? Para Josso (2004), as narrativas biográficas de professores podem ser consideradas como um caminho para a compreensão do processo de formação, por promoverem:

[...] processo auto-reflexivo, que obriga a um olhar retrospectivo e prospectivo, tem de ser compreendido como uma atividade de auto-interpretação crítica e de tomada de consciência da relatividade social, histórica e cultural das referências interiorizadas pelo sujeito e, por isso mesmo, constitutivas da dimensão cognitiva da sua objetividade (JOSSO, 2004, p. 60).

Narrar uma experiência possibilita um duplo movimento: pensar a prática, o trabalho dos professores no cotidiano da escola, mas também na perspectiva da pesquisa, produzir conhecimento, tornar público, coletivo, fortalecer a dimensão política da escola.

$\mathrm{Na}$ obra de Benjamin, os fragmentos rememorados não tratam apenas de uma experiência particular. $\mathrm{O}$ foco de Benjamin está naquilo que as narrativas podem evocar em quem com elas se relaciona: "sua intenção não é fixar o conteúdo do que é dito em sua própria vida, mas torná-lo comunicável na ampla e complexa esfera da cultura (PEREIRA, 2012, p. 43). 
Ao ressaltar que uma época não se deixa capturar por seus contemporâneos a partir dos grandes movimentos, mas que são os fragmentos constitutivos do cotidiano, pequenos detalhes, os estilhaços das grandes transformações, Benjamin (1994), sem preocupar-se em fazer uso do que é considerado valioso para desenvolver seu conceito de história, traz os resíduos da história e aplica a ela o princípio da montagem; "Isto é: erguer as grandes construções a partir de elementos minúsculos, recortados com clareza e precisão. E, mesmo, descobrir na análise do pequeno momento individual o cristal do acontecimento total" (BENJAMIN, 2006, p. 503).

Para Pereira (2012, p. 29), a tônica presente na filosofia de Benjamin de transitar entre as diferentes dimensões, "o pequeno e o grande, o fragmento e o todo, o individual e o social, o instante e a época, a experiência da infância e a experiência da vida", é uma consistente metodologia de estudo. A autora pondera que “os conceitos de 'pequeno' e 'grande' são desenhados e significados a partir de relações éticas, estéticas e epistemológicas” (PEREIRA, 2012, p. 29).

Nesse sentido, as narrativas tratadas neste texto mostram resíduos, desvios, escapes de um processo de formação que compreende a importância dos diálogos que não começaram com a professora, e das perguntas que não foram feitas por ela. A aposta na alteridade entre as crianças e a professora como possibilidade de resgatar a faculdade de intercambiar experiências e assim, dialogicamente, produzir conhecimento, autoriza a adulta, professora e pesquisadora, a contar sobre o que foi possível viver e ouvir delas nessa relação. O caderno com os registros dessas narrativas converte-se assim, em empiria de pesquisa. Guardadas estavam inquietações e indagações; vivências e histórias; a voz da professora e as vozes de diversos outros.

Considerando as discussões que envolvem as questões éticas na pesquisa com crianças, seus nomes são fictícios e, para orientar o leitor, os diálogos como material empírico aparecem no texto sempre seguidos dos contextos em que foram produzidos. A idade das crianças está indicada nos eventos no corpo do texto, tratando do contexto da educação infantil ao referir-se às de quatro e cinco anos, e do ensino fundamental às de seis a nove anos.

As narrativas demandaram o desafio de olhar de "fora", mas também de "dentro". Nas palavras de Buber, "começar consigo, mas não terminar consigo; partir de si, mas não ter a si mesmo como fim" (BUBER, 2011, p. 38). O fim deve ser o mundo, e o que podemos contribuir com ele. Nesse sentido, é possível pensar as narrativas dos professores para além de uma perspectiva individual do trabalho, mas coletiva, social.

Para Clandinin e Connelly (2011, p. 18), "uma verdadeira pesquisa narrativa é um processo dinâmico de viver e contar histórias, e reviver e recontar histórias, não somente aquelas que os participantes contam, mas aquelas também 
dos pesquisadores". Para os autores, o trabalho da narrativa como metodologia de estudo considera como material empírico a narrativa oral ou escrita.

Assim, diferentes autores têm apontado a importância dos registros dos professores em seus cadernos e diários como possibilidade de um trabalho investigativo sobre o cotidiano.

[...] os registros são portadores de histórias - histórias das práticas (dos equívocos, dos acertos) e das teorias que as fundamentam (mesmo que não estejam explicitadas, pois o registro possibilita esse olhar para o que está por detrás das práticas). Histórias dos afetos e das parcerias, marcadas pelas pessoas que constituem e complementam a nossa formação; histórias de um tempo e de um espaço vividos (FUJIKAWA, 2007, p. 250).

Ao escrever sobre as experiências, o professor reconstrói sua compreensão a respeito do conhecimento analisando-o, agora, de outro lugar e com outros olhares. Para Mendes (2007), a experiência do professor de escrita de sua própria prática não se restringe unicamente à estrutura do texto: "Narrar o que se faz, no sentido de dizer-se, revelar-se, expor-se, constitui-se enquanto processo de autoconhecimento" (MENDES, 2007, p. 20). Para Cunha e Nunes, a escrita do professor pode ser "ferramenta de refexão biográfica a respeito da formação inicial e continuada, momento em que são expostos os desafios, as dificuldades e as crises da vida profissional, a partir de lembranças sobre o passado escolar e das reflexões sobre o presente e o devir" (CUNHA; MENDES, 2017, p. 9).

Assim, registros guardados, ao serem revisitados podem produzir novos sentidos, reflexões nunca feitas. A escrita guarda o lugar da lembrança, mas também oferece outras possibilidades.

Parece ser nesse encontro entre o "infinitamente pequeno" e o "finitamente grande" entre o "geral" e o "particular", entre o "objetivo" e o "subjetivo" que essa tendência teórico/metodológica se apresenta cada vez mais como um recurso interessante para se pensar a formação docente, sobretudo a formação continuada na docência. Por que refletir sobre o meu passado e presente é importante para o futuro da minha profissão? (CUNHA; NUNES, 2017, p. 10). 
A narrativa apresenta-se como caminho de resgate da memória no sentido de revelar uma experiência significativa, possibilitando no presente a ressignificação do vivido. A escrita de si favorece um exercício de compreensão, interpretação e reflexão da prática do professor, por permitir:

Explicitar a singularidade e, com ela vislumbrar o universal, perceber o caráter processual da formação e da vida, articulando espaços, tempos e as diferentes dimensões de nós mesmos, em busca de uma sabedoria de vida (JOSSO, 2004, p. 9).

O exercício de escrita possibilita o lugar de autoria dos professores. A organização das memórias em texto ressignifica a experiência, potencializa o olhar para as lembranças do passado a partir da análise no presente. Nesse sentido, para a organização das narrativas, foi possível encontrar contribuições na obra de Benjamin (1994), em especial quando o autor apresenta um de seus personagens centrais: o colecionador. Ao trazer a concepção de conhecimento como coleção, afirma a necessidade de descontextualizar um objeto para que este funcione como texto. $O$ colecionador é capaz de fazer a descontextualização do objeto e, nesse caso, descontextualizar as narrativas, atribuindo a elas os diferentes sentidos possíveis, para, em seguida, reuni-las pelo que havia em comum a partir de um tema. A aproximação com base no que apresentam em comum é o que possibilita o efeito de coleção. Dessa forma, as narrativas do item a seguir foram organizadas em duas coleções no sentido benjaminiano: "Diálogos que convidam a olhar o outro" reúne pequenos gestos, sutilezas, no cotidiano escolar; já a coleção "Diálogos de ensinar e aprender" trata de desvios, rupturas, na prática pedagógica.

\section{Diálogos entre a professora e a alteridade da infância}

Olhar a criança como um outro implica estabelecer um diálogo com ela. Contudo, para BENJAMIM (1995, p. 23), "a liberdade do diálogo está se perdendo". Cada vez mais as pessoas conversam sobre superficialidades; o que diz respeito a preocupações e necessidades fica em segundo plano. Cada um se compromete com "as ilusões óticas de seu próprio ponto de vista isolado"; preso no seu próprio mundo, perde "o olhar para o contorno da pessoa humana" (BENJAMIN, 1995, p. 24). 
A superficialidade no diálogo, que não permite que falemos de nós, impedindo a construção de uma relação que confronte, altere, é tratada por Buber como "palavreado": o oposto da conversação genuína, constituída pela autenticidade que supera a aparência e é livre "de toda vontade de parecer" (BUBER, 2009, p. 155). Em sua obra, o autor apresenta três espécies de diálogo: o autêntico, o monólogo disfarçado de diálogo e o técnico.

No diálogo autêntico, "cada um dos participantes tem de fato em mente o outro ou os outros na sua presença e no seu modo de ser e a eles se volta com a intenção de estabelecer entre ele e si próprio uma reciprocidade viva" (BUBER, 2009 , p. 54). Há intenção em ouvir o outro e não apenas em falar. Para o autor, esse diálogo é raro.

O monólogo disfarçado de diálogo acontece quando duas ou mais pessoas estão reunidas e falam, cada um consigo mesmo (BUBER, 2009). Não há escuta do outro, esse não é considerado como presença no diálogo.

[..] uma conversação, que não é determinada nem pela necessidade de comunicar algo, nem por aquela de aprender algo, nem de influenciar alguém, nem de entrar em contato com alguém, mas é determinada unicamente pelo desejo de ver confirmada a própria autoconfiança, decifrando no outro a impressão deixada, ou de tê-la reforçada quando vacilante; uma conversa amistosa, na qual cada um se vê a si próprio como absoluto e legítimo e ao outro como relativizado e questionável (BUBER, 2009, p. 54).

O diálogo técnico é "movido pela necessidade de entendimento objetivo" (BUBER, 2009, p. 54). Os participantes desse diálogo mantêm uma conversação a fim de ter uma explicação sobre algo. Esse diálogo é necessário e não há nada de errado com ele. Entretanto, é preciso pensar como nós, professores, nos inserimos, quando a criança rompe o diálogo técnico. 


\section{Diálogos que convidam a olhar o outro}

\section{Uma volta}

As crianças estavam todas sentadas, enquanto eu escrevia no quadro a lenda da loira do banheiro que era ditada por eles. De repente, Felipe levantou-se do lugar e deu uma volta em torno da sala. Seu movimento chamou minha atenção e da turma. Olhei para ele como quem pergunta o que está acontecendo, e ele fez sinal com as mãos para que eu aguardasse. Professora: Está tudo bem, Felipe?

Felipe fez sinal com a cabeça que sim, terminou a volta e sentou no seu lugar. Continuei a escrita e no término da atividade chamei Felipe para conversar. Professora: Está tudo bem com você? Você fez sinal para eu esperar. Felipe (9 anos): Está. É que eu queria soltar um pum e não queria sair da sala. Estava com medo dessa história. Se eu ficasse no meu lugar todo mundo ia saber que fui eu, mas quando a gente está andando ninguém sabe quem soltou o pum (SCRAMINGNON, 2017).

Felipe rompe com o diálogo técnico deixando a professora no lugar de quem não tem resposta, porque quem fala é a criança: de uma necessidade física, humana. Como professores, nos colocamos muitas vezes no lugar de quem precisa saber de tudo e as crianças mostram que nem tudo é de nossa conta e que mesmo com toda pretensão não daremos conta de tudo. Dessa forma, educação, para Buber, não é um ato impositivo, mas uma relação que exige abertura e requer confiança, cujo pressuposto é a relação imediata com o outro:

A confiança é algo que, obviamente, não se obtém quando nos esforçamos em adquiri-la, mas, sim, na medida em que se participa de forma imediata e franca da vida dos educandos e quando se toma para si a responsabilidade que daí surge (BUBER, 2003a, p. 41).

Ao tratar da educação como relação, Buber ressalta que essa educação tem que ser em defesa do diálogo como fundamento, pois seu princípio básico é a abertura ao outro. A escuta da criança é um caminho para relações na escola que buscam a quebra da frieza. 


\section{"Ainda não consigo"}

Durante a brincadeira de galinha choca, José (6 anos) chora impaciente porque nenhum colega escondeu atrás de suas costas o objeto para que ele pudesse levantar e correr.

Professora: José, não precisa chorar. Vai chegar sua vez. É só esperar. Chorando, José responde: Eu sei que tenho que esperar, mas é que ainda não consigo não chorar quando eu quero uma coisa (SCRAMINGNON, 2017).

Há algo de "insondável com que as palavras da infância fazem frente aos adultos" (BENJAMIN, 1995, p. 81). "Não precisa chorar", uma frase tão corriqueira e quase automática dita às crianças leva José a responder de um jeito nada comum: "eu já sei, mas ainda não consigo". O desejo de brincar e a impaciência com a espera têm importâncias diferentes para ambos. A fala da professora que olha para o choro como algo desnecessário, afinal de contas, para ela, era apenas uma brincadeira, provoca no menino uma resposta desconhecida.

Para Benjamin (BENJAMIN, 1995, p. 37-40), as crianças são "indizivelmente concernidas pelo acontecer"; "estão ligadas no aqui e agora, tudo lhes acontece"; "atrás da cortina tornam-se elas mesmas algo ondulante e branco". O "ainda não consigo" apresentado como uma fraqueza infantil aponta para uma verdade que expõe a "experiência preciosa e essencial ao homem, do seu desajustamento em relação ao mundo, sua insegurança primeira, enfim, sua não-soberania", assim entende Gagnebin (2005, p. 180). A autora esclarece que, para Benjamin, a criança não é ingênua ou inocente, mas tem certa inabilidade para lidar com o mundo em oposição à segurança dos adultos.

O novo, trazido pelas crianças, está em processo e sobre ele não há controle. Trazem à tona questões que mobilizam o olhar diferente para o que estamos acostumados a ver. São formas e maneiras de interpretar experiências, valores e saberes que têm produzido e revelado como próprios de seu tempo de vida, ensinando formas diferentes de pensar no outro. 


\title{
"Vai todo mundo ficar quieto"
}

\begin{abstract}
Durante a aula tive uma indisposição e passei mal na frente das crianças. Enquanto estava sentada me recuperando, Karina entrou na sala com a diretora.

Diretora: Elas foram me chamar, disseram que você estava passando mal. Karina (9 anos): Gabriela, a gente já pediu para a diretora ligar para o seu pai vir te buscar. Pode ir que vai todo mundo ficar quieto (SCRAMINGNON, 2017).
\end{abstract}

$\mathrm{Na}$ ótica as crianças, ficar quieto pode ser uma forma de cuidado com a professora que está passando mal. Envolvidas e comprometidas em dar uma resposta humana a um pedido de ajuda, as crianças mostram como são capazes de cuidar dos adultos. No modo de perceber, indicam atitude e posição diante do outro.

E como perceber o outro? Como conhecê-lo? Para Buber, são três as maneiras pelas quais podemos perceber um homem diante dos nossos olhos: observar, contemplar e tomar conhecimento íntimo. "O observador está inteiramente concentrado em gravar na sua mente o homem que observa, em 'anotá-lo'. Ele o perscruta e o desenha". Já o contemplador não está absolutamente concentrado: "Ele se coloca numa posição que lhe permite ver o objeto livremente e espera despreocupado aquilo que a ele se apresentará" (BUBER, 2009, p. 41). A terceira forma de perceber implica mais: algo é transmitido, acolhido, aceito, recebido. Assim, olhar o outro exige atenção. Reconhecer o outro como um legítimo outro é um passo para se responsabilizar por ele. Não se trata apenas de sentirse responsável, mas traduzir a responsabilidade em ação.

\section{Sentimento}

Durante a leitura de uma história, Jordana interrompe e indaga:

Jordana (8 anos): Estou sentindo uma coisa que eu acho que é sentimento. Professora, todo mundo tem sentimento? Todo mundo sente o que eu estou sentindo?

Professora: As pessoas podem sentir muitas coisas, mas não sei se todo mundo sente o que você está sentindo.

Jordana: É uma coisa diferente (SCRAMINGNON, 2017). 
Os homens possuem sentimentos, eles residem no homem (Buber, 2003b). E, numa hora receptiva da vida, "encontra-me um homem em quem há alguma coisa, que eu não consigo captar de uma forma objetiva, que 'diz algo' a mim". E esse algo pode ser uma pergunta: "Todo mundo sente o que estou sentindo?" "Isto não significa de forma alguma que esta coisa me diga como este homem é, o que se passa nele ou coisa semelhante" (BUBER, 2009, p. 42).

Só Jordana sabia o que estava sentindo, e eu, o que senti ao ouvi-la. Não era possível saber se sentíamos a mesma coisa, mas o que senti embargou minha voz e quase impediu a continuidade da leitura. A menina conseguiu ouvir o que estava sentindo e disse da possibilidade humana de vivenciarmos experiências de escuta de nós mesmos. O que o outro me diz "transmite algo a mim, transmite algo que se introduz dentro da minha própria vida. Pode ser algo sobre este homem [...] mas pode ser também algo sobre mim” (BUBER, 2009, p. 42). $\mathrm{Na}$ escola, durante a leitura de uma história, a criança ajuda a lembrar que as instituições também são vivas e dinâmicas, especialmente humanizadas pelos sentimentos e encontros que nela ocorrem. A vida, mesmo dentro da escola, pode ser humanizada com práticas que possam ter outros contornos.

\section{Diálogos de ensinar e aprender}

\section{Só falo em particular}

Em uma página do livro didático, a proposta era as crianças desenharem suas famílias e compartilharem com a turma os desenhos feitos. Quando mostravam os desenhos feitos para a turma, chegou a vez de Vítor, que comentou: Quero falar em particular com você.

Pedi uns minutos para a turma e me distanciei com ele.

Vítor (9 anos): Eu só falo da minha família se for em particular.

Professora: Então você não quer mostrar seu desenho para a turma?

Vítor: Não desenhei porque não quero falar da minha família para todo mundo. Tem gente da minha família que eu não gosto e eu não quis desenhar.

Entramos na sala e ao retomarmos a atividade Vítor comentou com a turma: Eu não vou mostrar porque só falo da minha família em particular (SCRAMINGNON, 2017). 
A naturalidade suposta com que algumas práticas acontecem na escola impede o diálogo com as crianças e suas singularidades. Partir do pressuposto de que desenhar ou falar da família é algo simples é desconsiderar a experiência de cada um. É isso que Vítor faz lembrar ao renunciar à atividade. Ao trazer a sua história, ele fala do desafio de voltar-se para o outro e da possibilidade criadora das crianças de fazerem diferente diante do que parece ser sempre da mesma forma. O que fazer com esse potencial? Como não desperdiçá-lo? Viver significa ser alvo da palavra dirigida, e as crianças convidam a respondermos ao espontâneo que elas trazem, abrindo espaço para a incerteza, para a vulnerabilidade, convidando o professor a repensar sua prática.

Escutar as crianças e suas histórias é abrir espaço para uma nova racionalidade nas instituições. Nessa perspectiva, a prática educativa envolve o "espontâneo" (BUBER, 2003a, p. 13) que surge nas relações, dando ao professor o lugar de mediador que acolhe a pluralidade e a multiplicidade das manifestações infantis, fazendo da educação uma experiência de reciprocidade.

\section{Bilhete}

Flávia, de uma turma de pré-escola, próximo à hora da saída, após receber a agenda com um bilhete colado, disse:

Flávia (4 anos): Professora, você pode ler o bilhete da agenda?

Ao perguntar o porquê, ela respondeu:

Flávia: É que quando eu leio para a minha avó ela entende, mas quando ela lê sozinha o que você escreveu ela não entende.

$\mathrm{Na}$ mesma hora li para ela e, enquanto reunia a turma para fazer a leitura, Flávia, com a agenda na mão, adiantava para as crianças o texto do bilhete. $\mathrm{Na}$ hora da saída, no portão da escola, ao encontrar a avó, tirou a agenda da mochila e fez a leitura do bilhete (SCRAMINGNON, 2017).

O que Flávia estava dizendo era que sua avó não sabia ler e que ela precisava ter conhecimento do conteúdo dos bilhetes para mantê-la informada. A menina morava com sua avó, que era analfabeta, e uma irmã menor. Seu pedido mostrou a importância de ler constantemente com as crianças os bilhetes enviados para as famílias; e para além da leitura como prática que compõe o trabalho na Educação Infantil, o que Flávia ensina é que é possível repensar a prática a partir das questões trazidas pelas crianças. Ela diz da possibilidade de aprendermos com elas, de fazermos de outra forma na escola. 


\section{Ensaio}

A escola apresentou como proposta de trabalho a realização de uma festa em comemoração ao dia das mães, com uma participação musical das crianças. Ao iniciar o ensaio, percebi que algumas delas permaneceram sentadas onde estavam e não demostravam interesse.

Professora: Por que vocês não estão ensaiando?

Sandra (5 anos): Não vou ensaiar porque minha mãe não vai poder vir. Ela trabalha.

Olívia: (5 anos): Não moro com minha mãe e minha avó não pode vir. Marcelo (5 anos): A minha mãe disse que não vem porque ela não pode trazer um prato de doce (SCRAMINGNON, 2017).

Desestabilizada com a situação, parei o ensaio e, na conversa com elas concluí que aquela comemoração não tinha significado para a maioria da turma. Dei-me conta da realidade das famílias e me questionei: quais seriam as mães que realmente poderiam estar na escola para uma comemoração às $11 \mathrm{~h}$ da manhã, quando muitas trabalhavam longe da comunidade em que moravam e não teriam a facilidade de sair do trabalho para participar de uma festa na escola numa sextafeira? Será que a música que elas iriam cantar representava o sentimento que tinham por suas mães, já que a escolha da música havia sido feita pela escola? Era um desejo das crianças? Para aquele grupo, era significativa aquela festa?

Reconhecer as crianças como capazes de expressar sentimentos e pensamentos é assumir que "há realidades sociais que só a partir do ponto de vista das crianças e dos seus universos específicos podem ser descobertas, apreendidas e analisadas" (SARMENTO; PINTO, 1997, p. 65).

\section{Caneta vermelha}

No momento de devolver o caderno corrigido para Carla, ela comenta: Carla (8 anos): Eu não queria que você corrigisse meu caderno assim. Professora: Assim como?

Carla: De caneta vermelha. Corrige de lápis para eu apagar depois. Meu caderno fica feio, todo rabiscado. Não consigo apagar e nem entender o que está escrito (SCRAMINGNON, 2017). 
O que inicialmente podia parecer elementar me fez pensar quantas vezes muitos de nós, professores, passamos horas corrigindo cadernos que nos tomam um tempo enorme, quando poderíamos fazer tantas outras coisas em nossa relação com as crianças que, como bem disse a menina, não entendem o que fazemos. Carla me fez pensar sobre o sentido da correção dos trabalhos e mudar minha prática. Seu comentário provocou uma indagação: para quem corrigimos os cadernos? Para as crianças ou para os responsáveis? Não seria realmente necessário ter cuidado com esse objeto tão particular que é o caderno de alguém? Enquanto professora, diariamente era invasiva diante da forma de organização e escrita das crianças. O questionamento de Carla me fez pensar que eu, adulta, professora, tinha uma forma peculiar de registro nos meus cadernos, e o quanto estava sendo desrespeitosa com a escrita das crianças. "A autoria se concretiza nas marcas que deixamos no mundo e nas marcas que o mundo inscreve em nós; o que fazemos, dizemos, escrevemos, construímos, o que é escrito no nosso corpo, nas nossas ações e produções" (KRAMER, 2013, p. 311). A produção das crianças tinha a marca da caneta vermelha da professora, que passava literalmente "por cima" da autoria das crianças.

E, diante de tudo que ouvi, o que meu olhar para essa história constrói ao confrontá-la com minha trajetória de professora e com as crianças com quem dialoguei? E para quê escutar senão para responder? "A responsabilidade significa sempre responsabilidade diante de alguém. Responsabilidade para consigo mesmo é uma ilusão" (BUBER, 2012, p. 79). Nesse sentido, ao escutar recordações e resgatar memórias, foi revelada uma experiência significativa na relação com as crianças. As questões trazidas por elas deslocam a professora de suas certezas. Elas retiram as coisas do seu lugar habitual para dar-lhes novos sentidos: nada é inteiro, tudo é partido em muitos significados. As crianças "renovam a existência por meio de uma prática centuplicada e jamais complicada"(BENJAMIN, 1995, p. 229). Gagnebin (2007) afirma ainda que o "in" (in-fância), que para o pensamento humano significa ausência, em Benjamin é o espaço que possibilita o desnudamento e a miséria, no limiar da existência e da fala. Esse "in" não é de ausência, incapacidade, incompetência, mas de incompletude, o que torna possível a invenção.

\section{Considerações}

O debate proposto neste texto fez menção ao convite das crianças à professora a uma visada de questões relacionadas ao trabalho cotidiano na 
escola. Nas narrativas apresentadas, o impulso da palavra alheia - das crianças - disparou diálogos para pensar a docência. As questões colocadas por elas provocaram, por parte da professora, réplicas, necessidade de se perguntar o que estava fazendo e como estava fazendo, respostas que exigiam posicionamento.

Nas narrativas, o passado ressignificado se impôs mostrando como as crianças fazem perguntas que ajudam os professores a se reencontrarem. O diálogo com elas mobilizou memórias permitindo ouvir a minha própria história: de adulta, professora, pesquisadora. Durante esse processo, a escrita, ao fisgar os sentidos desconhecidos, mostrou o quanto a reflexão, além de falar das crianças do tempo presente, fala também da curiosidade pela forma como as crianças atribuem sentido ao mundo, e de uma dimensão peculiar do trabalho dos professores: a descoberta da criança como um outro que nos interpela e provoca. Mais do que um relato, a narrativa reflete sobre o processo vivido e explicita o sentido que não é descoberto, mas refeito: o lugar da docência vai se constituindo na relação com o contexto social, histórico, cultural, com os sujeitos, nos processos formativos.

Foi no diálogo com minhas próprias memórias que fui provocada a me perguntar: de que forma o investimento no processo de formação pode ter ajudado a construir registros como produção de um outro saber da própria prática? Por que as memórias escritas tomaram determinada direção na minha trajetória de professora? O que estava escrito teve sempre o mesmo sentido? Como, no presente, o exercício de debruçar-se sobre a coleção de memórias pôde possibilitar diferentes compreensões para fragmentos constitutivos do tornar-se professora? Como aprender a escrever sobre a própria prática, narrar, tornando a experiência compartilhada? Em que momento a minha história encontra com a história de outros professores? Nesse sentido, é importante pensarmos se os projetos de formação têm possibilitado que os professores saiam da superficialidade, compreendendo aspectos fundamentais dessa profissão a fim de que se debrucem sobre suas práticas. Vale enfatizar a necessidade de investimentos de espaços e tempos em que possam narrar suas experiências, contar suas histórias, registrar, dizer, tornar a experiência coletiva, compartilhada. Entender que as dimensões temporais parecem determinantes nesse processo tem a ver com as oportunidades de produção dessas narrativas pelos professores, defendidas nesta discussão como um direito.

Faz-se necessário debater a função política da formação, considerando que o modo como os professores são percebidos pode ou não garantir a concretização do direito de serem narradores de suas histórias, que, por sua vez, trazem novas formas de olhar para o que estamos acostumados. Para Benjamin (1994) a narrativa não é para informar. Na história de uma professora de crianças a experiência com elas foi fundante para formar. "Quem escuta uma história 
está em companhia do narrador; mesmo quem a lê partilha dessa companhia" (BENJAMIN, 1994, p. 213). Nesse encontro reside a possibilidade de fazer o 'novo no sempre igual'. Mas, para isso, é preciso vínculo, presença. É preciso ter quem ouça!

\section{REFERÊNCIAS}

BENJAMIN, Walter. Obras escolhidas. Magia e técnica, arte e política. Ensaios sobre literatura e história da cultura. Tradução de Sérgio Paulo Rouanet. 7. ed. São Paulo: Brasiliense, 1994.

BENJAMIN, Walter. Obras escolhidas II. Rua de mão única. Tradução de Rubens Rodrigues Torres Filho e José Carlos Martins Barbosa. 5. ed. São Paulo: Brasiliense, 1995.

BENJAMIN, Walter. Passagens. Tradução de Cleonice Paes Barreto Mourão e Irene Aron. Belo Horizonte: Editora UFMG; São Paulo: Imprensa Oficial do Estado de São Paulo, 2006.

BUBER, Martin. Do diálogo e do dialógico. Tradução de Marta Ekstein de Souza Queiroz e Regina Weinberg. São Paulo: Perspectiva, 2009.

BUBER, Martin. El caminho del ser humano y otros escritos. Tradución y notas Carlos Díaz. Madrid, España: Fundación Emmanuel Mounier, 2003a.

BUBER, Martin. Eu e tu. Tradução de Newton Aquiles von Zuben. 6. ed. São Paulo: Centauro, 2003b.

BUBER, Martin. O caminho do homem segundo o ensinamento chassídico. Tradução de Claudia Abeling. São Paulo: É Realizações, 2011.

BUBER, Martin. Sobre comunidade. Tradução de Newton Aquiles von Zuben. São Paulo: Perspectiva, 2012.

CLANDININ, D. Jean; CONELLY, F. Michael. Pesquisa narrativa: experiências e história na pesquisa qualitativa. Tradução de Grupo de Pesquisa Narrativa e Educação de Professores da Universidade Federal de Uberlândia. Uberlândia: EDUFU, 2011.

CUNHA, Maria Amália Almeida; NUNES, Célia Maria Fernandes. As biografias educativas como fonte de pesquisa e estudo no campo da formação docente: notas iniciais para uma discussão teórico/metodológica. Thema, Pelotas, v. 14, n. 2, p. 9-13, 2017. Disponível em: https://www.repositorio.ufop.br/bitstream/123456789/9503/1/ ARTIGO_BiografiasEducativasFonte.pdf. Acesso em: 15 jul. 2020. 
FUJIKAWA, Mônica Matie. A escrita como pretexto de reflexão da prática pedagógica e como estratégia de intervenção na formação de professores. In: PRADO, Guilherme Do Val Toledo; SOLIGO, Rosaura (org.). Porque escrever é fazer história: revelações, subversões, superações. São Paulo: Alínea, 2007. p. 229-243.

GAGNEBIN, Jeanne Marie. História e narração em Walter Benjamin. 2. ed. São Paulo: Perspectiva, 2007.

GAGNEBIN, Jeanne Marie. Sete aulas sobre linguagem, memória e história. 2. ed. Rio de Janeiro: Imago, 2005.

JOSSO, Marie Christine. Experiências de vida e formação. Tradução de José Claudino e Júlia Ferreira. São Paulo: Cortez, 2004.

KRAMER, Sonia. Formação e responsabilidade: escutando Mikhail Bakhtin e Martin Buber. In: KRAMER, Sonia; NUNES, Maria Fernanda.; CARVALHO, Maria Cristina (org.). Educação Infantil: formação e responsabilidade. Campinas, SP: Papirus, 2013. p. 309-329.

MENDES, Maria Francisca. Práticas, narrativas e reflexões no diário de uma professora de alfabetização. 2007. 153 p. Dissertação (Mestrado em Educação) Pontifícia Universidade Católica do Rio de Janeiro, Rio de Janeiro, 2007.

PEREIRA, Rita Marisa Ribes. Um pequeno mundo próprio inserido num mundo maior. In: PEREIRA, Rita Marisa Ribes; MACEDO, Nélia Mara Rezende (org.) Infância em pesquisa. Rio de Janeiro: NAU, 2012. p. 25-58.

SARMENTO, Manuel Jacinto; PINTO, Manuel (org.). As crianças: contextos e identidades. Braga: Universidade do Minho, 1997.

SCRAMINGNON, Gabriela Barreto da Silva. Ser criança, ser adulto, ser professor: encontros, diálogos e desvios com crianças de seis a dez anos. 2017. 167 p. Tese (Doutorado em Educação) - Pontifícia Universidade Católica do Rio de Janeiro, Rio de Janeiro, 2017.

Texto recebido em 03/08/2020.

Texto aprovado em 21/10/2020. 